Journal of Engineering and Applied Sciences 14 (16): 5942-5954, 2019

ISSN: 1816-949X

(C) Medwell Journals, 2019

\title{
Assessment of Integrating Wind Energy System on Iraqi Power Grid Capability Limit
}

\author{
${ }^{1}$ Yasir G. Rashid, ${ }^{1}$ Firas M. Tuaimah and ${ }^{2}$ Karwan J. Mohammed \\ ${ }^{1}$ Department of Electrical Engineering, College of Engineering, University of Baghdad, Baghdad, Iraq \\ ${ }^{2}$ Operation and Control Office, Ministry of Electricity, Baghdad, Iraq \\ yasir.ghazi1702@coeng.uobaghdad.edu.iq,Dr.firas@coeng.uobaghdad.edu.iq, \\ Karwanjabbar@yahoo.com
}

\begin{abstract}
When wind turbine generator are installed into the electric grid, the power quality is influenced. Now a days, strict installation recommendations typically prevail because of an absence of information on this subject. Therefore, it's far crucial to are expecting the impact of wind turbines on the electrical grid before the generators are installed. This study presents the proposed the impact integration wind energy on different performance parameters of a specified of power system. The proposed impact integration has been simulated using Power System Simulator for Engineer (PSS/E) Software Version 30.3 applied on the $132 \mathrm{kV}$ Iraqi grid system. The analysis techniques studied the total generation of slack bus, voltage profile, the power flow of transmission lines loaded, the active and reactive power losses. In this research, study of the impact of single and multiple wind farm site. Several scenarios with penetration levels from $25-100 \%$ and dispersion of wind generation have been investigated.
\end{abstract}

$\underline{\text { Key words: Power flow, renewable power sources, wind penetration, voltage profile, PSS/E, turbine generator }}$

\section{INTRODUCTION}

Electricity production from renewable energy sources has come below growing attention in latest many years. Approximately $22 \%$ of global electricity consumption is compensated by all types of renewable energy sources. Driven by technological innovations, cost reduction, government incentive programs and public demand for clean energy and wind energy is increasingly becoming mainstream, competing with not only other renewable energy sources but also with conventional fossil fuel based power generation units (Yaramasu et al., 2015). At the end of 2014, global cumulative wind power capacity reached 370 (GWs) which accounts for approximately $4 \%$ of the world's net electricity production (Yaramasu et al., 2015; GWEC., 2017).

Zirconia has properties that overcome the problem associated with alumina bioceramics i.e., the brittleness of that material. This is most evident in partially stabilized Zirconia $\left(3 \mathrm{Y}-\mathrm{ZrO}_{2}\right)$ which has a phase transformation toughening mechanism that helps prevent cracks from propagating. However, partially stabilized zirconia in the presence of bodily fluids undergoes an undesirable roughening of the surface and micro-cracking (Villafafila et al., 2007).
Over the past 35 years, the size of WTs has gradually increased and has currently reached a massive level of 10 (MWs). Due to the rapid integration of wind power into the electric grid, many concerns have emerged on the stable and secure operation of existing electric power systems. Grid code requirements have been updated and enforced in many countries on the grid connection of large-scale WTs and Wind Farms (WFs).

Wind energy is one of the fastest growing renewable energy sources and continues to flourish each year in many countries. The cumulative and annual installed wind power capacities worldwide are shown in Fig. 1 and 2, respectively. Data are presented collectively, according to the Global Wind Energy Council 2018 report (Sorensen, 2017). In this study a methodology, based on a Power Flow analysis (PF) is used to evaluate the effects of the wind turbine on the Iraqi power grid. The Newton-Raphson algorithm is applied in calculation of power systems voltage. The results are obtained for two cases of the network state: without the wind generator and with integration of the wind generator.

Load flow studies: Load flow studies are the mainstay of the planning, economic and control of a power system.

Corresponding Author: Yasir G. Rashid, Department of Electrical Engineering, College of Engineering, University of Baghdad, Baghdad, Iraq, yasir.ghazi1702@coeng.uobaghdad.edu.iq 


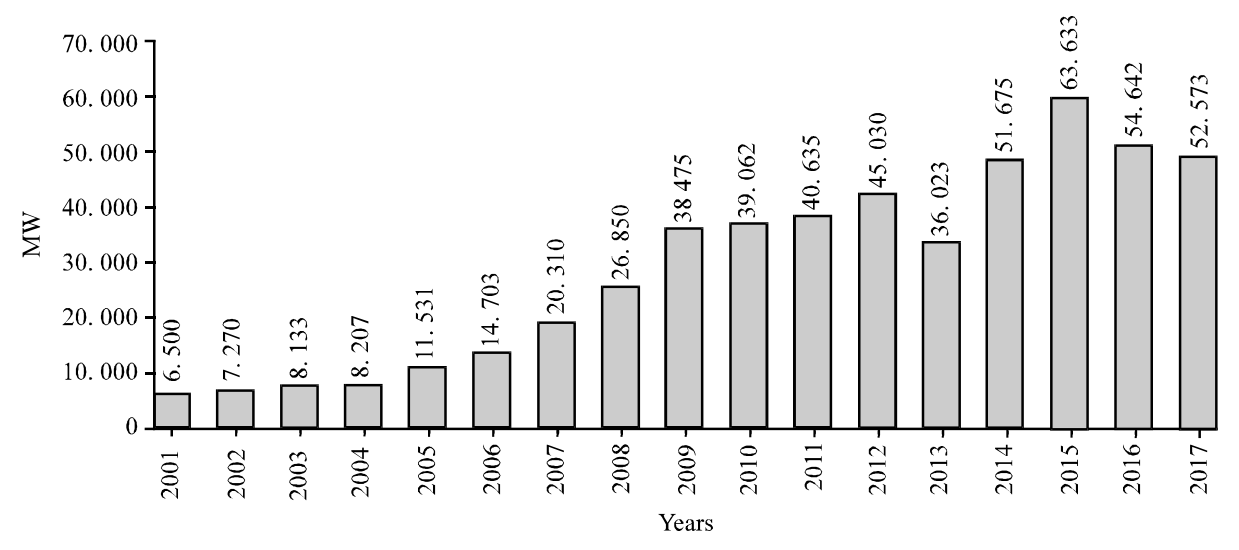

Fig. 1: Global and cumulative installed wind power from 2001-2017 (Sorensen, 2017)

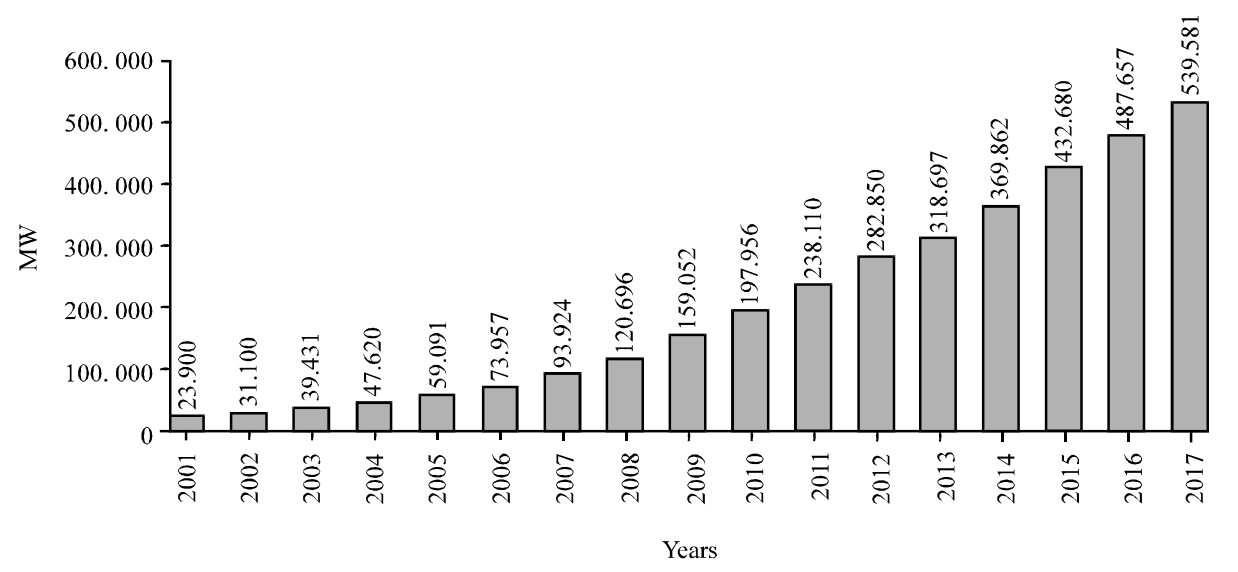

Fig. 2: Global annual installed wind power from 2001-2017 (Sorensen, 2017)

Study of load flow includes the calculation of voltages, current, power and power factor or reactive power at several point in an electrically networks under existing or contemplated conditionals of normal operation. Then incomplete definitional of powered flower needs knowledge's of fourteen invariables at reach bus (k) in the system:

- $\mathrm{P}_{\mathrm{K}}=$ Really or reactive powered

- $\mathrm{Q}_{\mathrm{K}}=$ Reactive powered

- $\mathrm{V}_{\mathrm{K}}=$ Voltages magnitudes

- $\theta_{\mathrm{K}}=$ Voltages phased angle

Only two of these are unknown prior to solving the problems and the aim of the load flow is to solve the remaining two's invariables at each bus (Villafafila et al., 2007).

\section{MATERIALS AND METHODS}

Problem formulation: Slack bus generation capacity constraints: The real power output of slack bus generation has be restricted within their respective lower and upper bounds (inequality constraints) as follows:

$$
P_{G j}^{\min } \leq P_{G j} \leq P_{G j}^{\max } \text { for } j=1,2, \ldots, n
$$

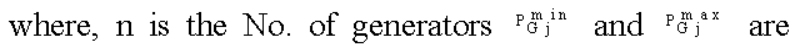
minimum and maximum power outputs of $\mathrm{jth}$ generating unit respectively.

Active and reactive power losses: The objective is to minimize the total active and reactive power losses in the transmission lines may be expressed as follows: 


$$
\begin{aligned}
& \mathrm{P}_{\mathrm{L}}=\sum_{\mathrm{k}=1}^{\mathrm{m}} \mathrm{G}_{\mathrm{K}}\left(\mathrm{V}_{\mathrm{i}}^{2}+\mathrm{V}_{\mathrm{j}}^{2} 2 \mathrm{~V}_{\mathrm{i}} \mathrm{V}_{\mathrm{j}} \cos \left(\delta_{\mathrm{i}}-\delta_{\mathrm{j}}\right)\right) \\
& \mathrm{Q}_{\mathrm{L}}=\sum_{\mathrm{k}=1}^{\mathrm{m}} \mathrm{B}_{\mathrm{K}}\left(\mathrm{V}_{\mathrm{i}}^{2}+\mathrm{V}_{\mathrm{j}}^{2} 2 \mathrm{~V}_{\mathrm{i}} \mathrm{V}_{\mathrm{j}} \sin \left(\delta_{\mathrm{i}}-\delta_{\mathrm{j}}\right)\right)
\end{aligned}
$$

Where:

$\mathrm{m}=$ The total number of lines in the system

$\mathrm{G}_{\mathrm{k}}=$ The conductance of the kth line

$B_{k}=$ The susceptance of the $k$ th line

$\mathrm{V}_{\mathrm{i}}=$ The voltage magnitude at bus $\mathrm{i}$

$\mathrm{V}_{\mathrm{j}}=$ The voltage magnitude at bus $\mathrm{j}$

$\mathrm{j} ; \delta_{\mathrm{i}}=$ The voltage angle at bus $\mathrm{i}$

I; $\delta_{i}=$ The voltage angle at bus $\mathrm{j}$ (Wood et al., 2013)

Voltage deviation: To have a good voltage performance, the voltage deviation at every load bus have to be made as small as possible. The voltage deviation $(\Delta \mathrm{v})$ to be minimized is given by Zehar and Sayah (2008).

$$
\Delta \mathrm{V}=\sum_{\mathrm{k}=1}^{\mathrm{N}_{\mathrm{PQ}}}\left|\mathrm{V}_{\mathrm{K}}-\mathrm{V}_{\mathrm{K}}^{\text {des }}\right|
$$

Where:

$\mathrm{N}_{\mathrm{PQ}}=$ The number of load buses

$\mathrm{v}_{\mathrm{K}}^{\text {des }}=$ The desired or target value of the voltage magnitude at load bus $\mathrm{k}$

Overloaded lines: This objective is to minimize the power flow in overloaded transmission lines; this objective is calculated for every line of the system. The lines loading have to be $<100 \%$. The active power and reactive power flow on lines can be applied as follows:

$$
\begin{gathered}
\mathrm{P}_{\mathrm{Gi}}-\mathrm{P}_{\mathrm{Di}}=\sum_{\mathrm{k}=1}^{\mathrm{m}} \mathrm{V}_{\mathrm{j}}\left(\mathrm{G}_{\mathrm{K}} \cos \left(\delta_{\mathrm{i}}-\delta_{\mathrm{j}}\right)+\mathrm{B}_{\mathrm{K}} \sin \left(\delta_{\mathrm{i}}-\delta_{\mathrm{j}}\right)\right)(4) \\
\mathrm{Q}_{\mathrm{Gi}}-\mathrm{Q}_{\mathrm{Di}}=\sum_{\mathrm{k}=1}^{\mathrm{m}} \mathrm{V}_{\mathrm{j}}\left(\mathrm{G}_{\mathrm{K}} \sin \left(\delta_{\mathrm{i}}-\delta_{\mathrm{j}}\right)+\mathrm{B}_{\mathrm{K}} \cos \left(\delta_{\mathrm{i}}-\delta_{\mathrm{j}}\right)\right)(5)
\end{gathered}
$$

Where:

$$
\begin{aligned}
\mathrm{P} & =\text { The real power generation at bus } \mathrm{i} \\
\mathrm{P}_{\mathrm{di}} & =\text { The real power demand at bus } \mathrm{i} \\
\mathrm{Q}_{\mathrm{di}} & =\text { The reactive power generation at bus } \mathrm{i} \\
\mathrm{Q}_{\mathrm{di}} & =\text { The reactive power demand at bus } \mathrm{i} \\
\mathrm{m} & =\text { The total number of buses in the system } \\
\mathrm{V}_{\mathrm{i}}= & \text { The voltage magnitude at bus } \mathrm{i} \\
\mathrm{V}_{\mathrm{i}}= & \text { The voltage magnitude at bus } \\
\mathrm{j}= & \text { The conductance of the kth line is the } \\
& \text { susceptance of the kth line } \\
\delta_{\mathrm{i}}= & \text { The voltage angle at bus } \\
\mathrm{i} \text { and } \delta_{\mathrm{j}}= & \text { The voltage angle at bus } \mathrm{j} \text { (Kalaivani and } \\
& \text { Kamaraj, 2012) }
\end{aligned}
$$

The best site choice for wind farms in Iraq: Selecting an appropriate site is key to the success of any renewable-energy project, financially and technically. This applies to every type of project from the smallest residential systems to the largest utility-scale projects. It also applies to every renewable-energy technology from wind to solar to biomass and others. Selecting the proper site and designing a turbine array to fit it are vital to ensuring that wind farms perform as expected. Site selection also plays a crucial role in the financial returns of the project, ease of construction, ongoing operations and maintenance and overall safety. As you'd expect an inappropriate site or illdesigned turbine array jeopardizes the project (Salman, 2015). Number of pointers to the things you will want to consider when selecting location wind farm.

Wind resource: Obviously, the wind speed is the crucial factor and determines how much electricity a wind turbine will generate each year. The wind speed needs to be measured on site prior to an installation if you want any degree of certainty as to the wind speed. More sophisticated prediction software tools are being developed and may, over the next few years, reduce the requirement for monitoring. For onshore wind projects, identify the wind class and whether it lines up with the cut-in speed and optimal wind speed for the proposed wind turbine. It is also important to evaluate whether nearby obstacles will cause turbulence to disrupt airflow access to the site and reduce turbine life. An industry rule of thumb the distance between a turbine and the nearest obstacle should be at least twice the turbine height, unless the turbine is more than twice the height of the obstacle in which case the distance can be less (Cetinay et al., 2017). Usually, sites are screened on the basis of a wind atlas and validated with wind measurements. Meteorological wind data alone is usually not sufficient for accurate siting of a large wind power project. Collection of site specific data for wind speed and direction is crucial to determining site potential in order to finance the project. Local winds are often monitored for a year or more and detailed wind maps constructed before wind generators are installed (Mirhosseini et al., 2011).

Wind Atlas of Iraq: In 2012, the maps were calculated by the Spanish Center for Renewable Energy (CENER) for the 
J. Eng. Applied Sci., 14 (16): 5942-5954, 2019

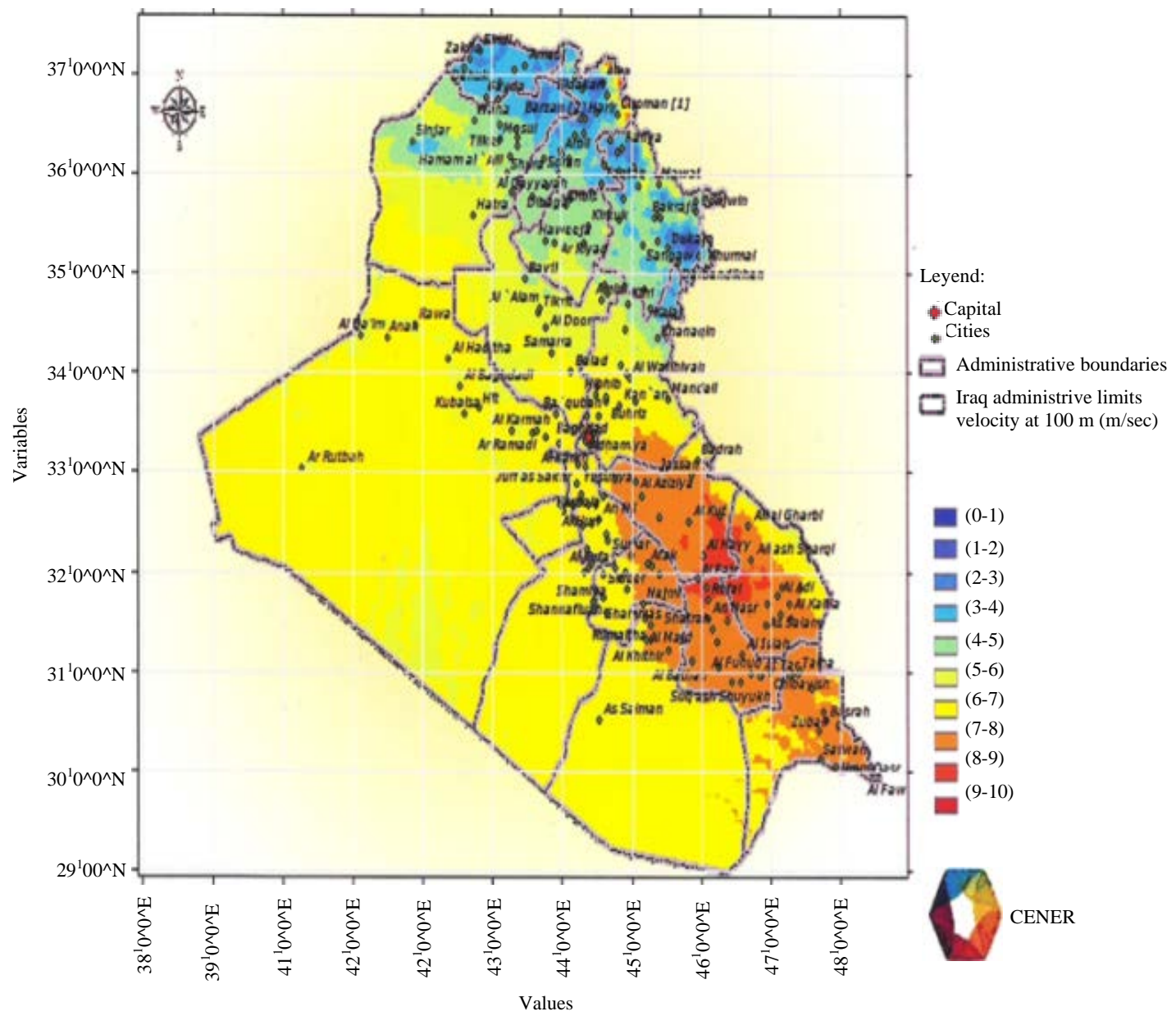

Fig. 3: Iraqi wind map for $100 \mathrm{~m}$

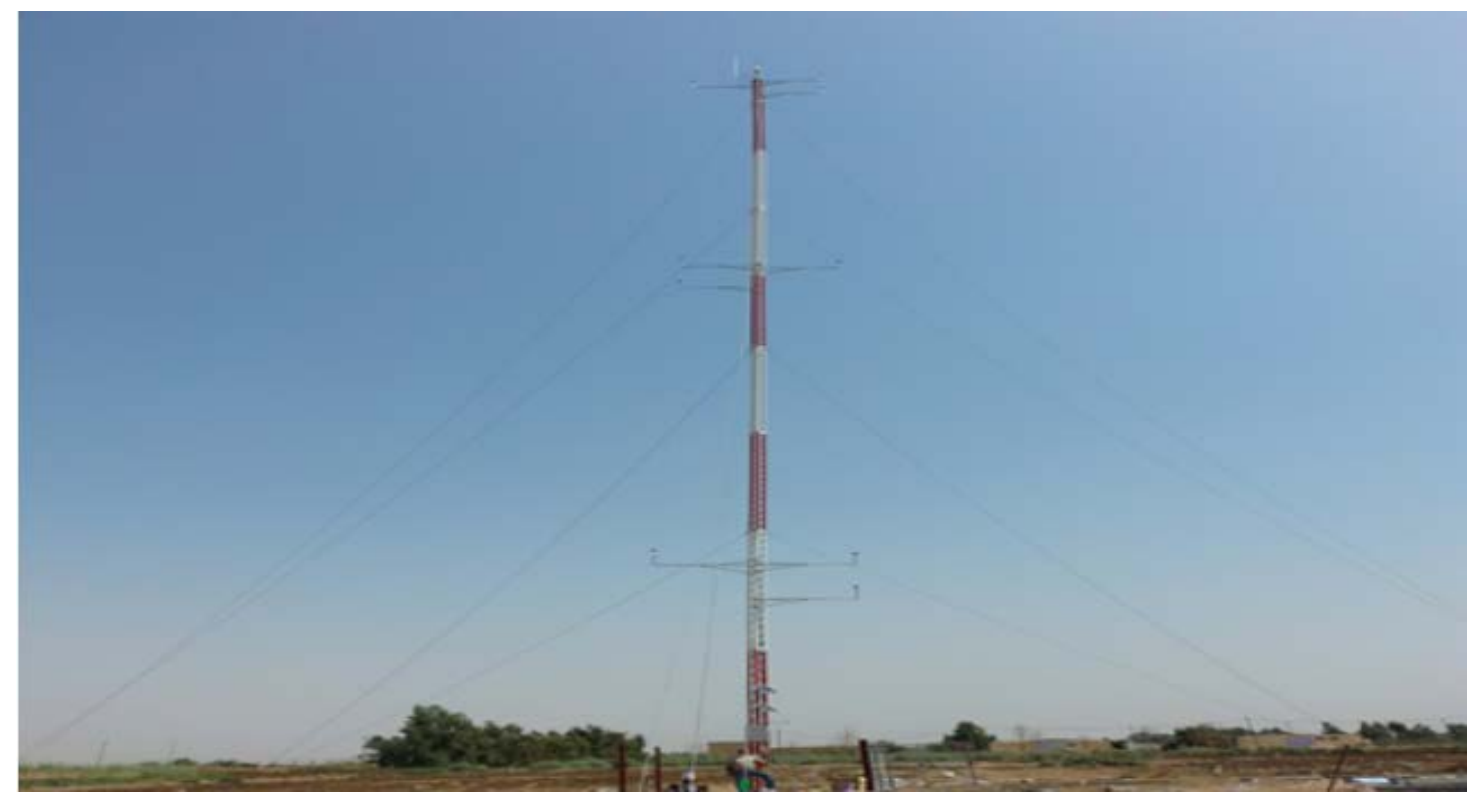

Fig. 4: The aerial tower 


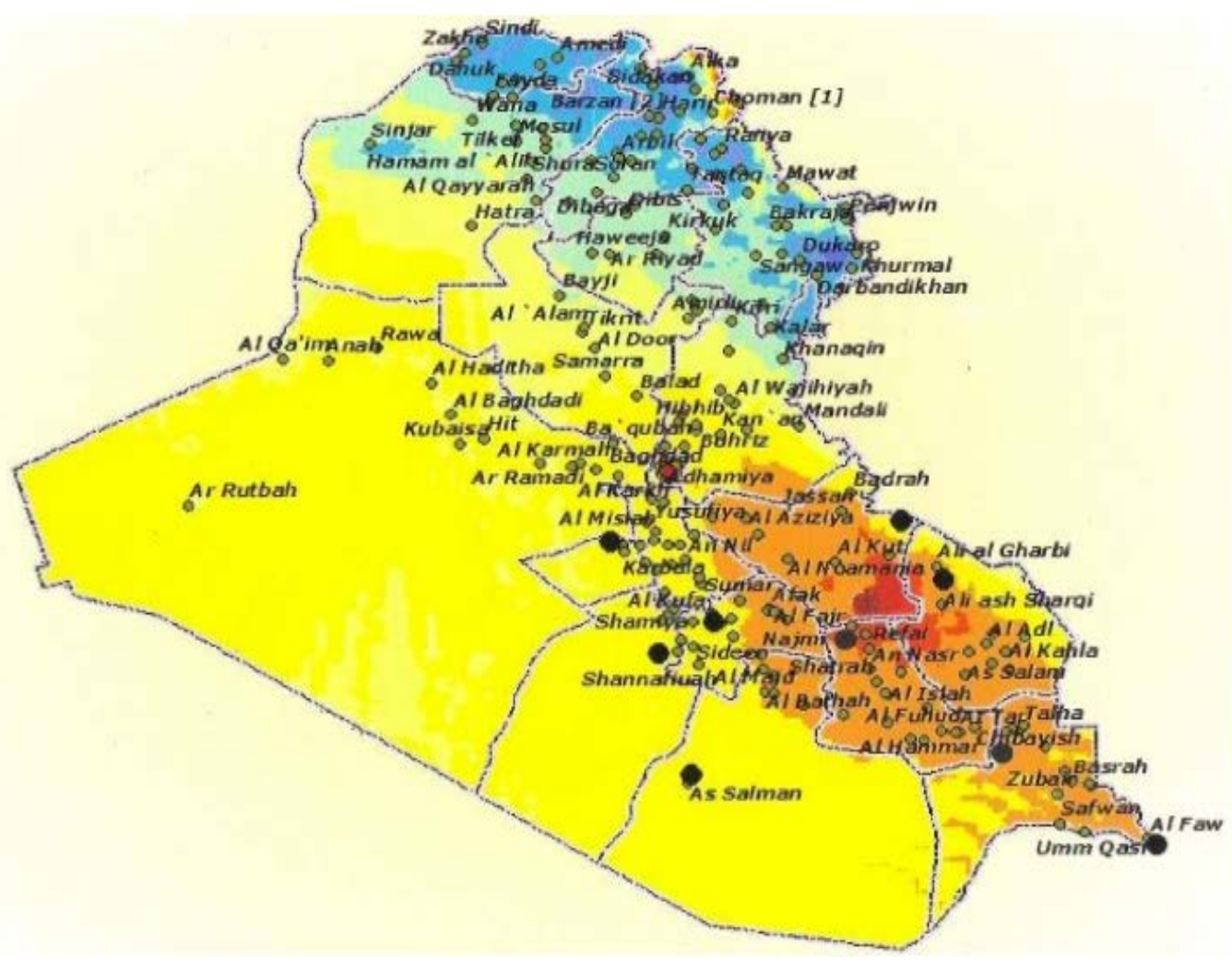

Fig. 5: Iraqi wind map for locations of the aerial tower

Iraqi Ministry of Science and Technology. Maps of wind density, Weibull $\mathrm{A}$ and Weibull $\mathrm{k}$ at 30,50 and $100 \mathrm{~m}$ height and with $5 \mathrm{~km}$ resolution. The period simulated is since, June 2003-2012. The maps are calculated by simulating the atmosphere conditions with SKIRON mesoscale model. GFS 12 UTC cycle from NCARANCEP is used as input. SKIRON long-term simulation is launched to cover the entire 9 years, generating hourly maps. Figure 3 shows the Iraqi wind map for $100 \mathrm{~m}$. Real wind Atlas depends on the field data in different locations in Iraq to obtain the real data of the wind speed at a location, installed an antenna tower at least $50 \mathrm{~m}$ high. The wind speed sensors are set at altitudes of 10,30 and $50 \mathrm{~m}$, wind direction sensors are installed at altitude 8,28 and $48 \mathrm{~m}$, the remaining sensors are installed at a height of $10 \mathrm{~m}$ show in Fig. 4. Everyone of aerial tower record the speed and direction of the wind every 10 $\min$ (52560 annual). Nine sites were selected to install the aerial tower in Fig. 5:

- Al-Shehabi, Al-Dujaili, Shaikh Saad-Wasit

- Al-Fajr-Dhi Qar

- Razzaza-Karbala
- Al- Shibaga-Najaf

- Al- Salman-Muthanna

- University of Al-Qâdisiyyah-Al-Qadisiyyah

- The Marshlands Musab-Basra

Turbine size: This is often restricted by the space you have available and planning restrictions. Small turbines can be installed in some circumstances under permitted development. Generally, the larger the rotor the more energy the turbine will capture. However, you will not always want to have the largest generator size (this will be stated as the maximum output in $\mathrm{kW}$ ). A large generator provides more resistance and can prevent a wind turbine starting in lower wind conditions, so, you may actually generate more electricity on a site with lower average wind speeds (Cetinay et al., 2017).

Available area for wind farm: How closely to space the turbines together is a major factor in wind farm design. The closer the turbines are together the more the upwind turbines block wind from their neighbors. However, spacing turbines far apart increases the costs of roads 
Table 1: Cases denoted by the changes in streamwise and spanwise spacing

\begin{tabular}{lll}
\hline Cases & Sx & Sz \\
\hline $\mathrm{A}$ & $6 \mathrm{D}$ & $3 \mathrm{D}$ \\
$\mathrm{B}$ & $3 \mathrm{D}$ & $3 \mathrm{D}$ \\
$\mathrm{C}$ & $3 \mathrm{D}$ & $1.5 \mathrm{D}$ \\
$\mathrm{D}$ & $6 \mathrm{D}$ & $1.5 \mathrm{D}$ \\
\hline
\end{tabular}

Table 2: Friction coefficient for various terrain characteristics (Zobaa and Bansal, 2011)

\begin{tabular}{lc}
\hline Terrain characteristics & Friction coefficient $(\alpha)$ \\
\hline Smooth hard ground, calm water & 0.10 \\
Tall grass on level ground & 0.15 \\
High crops, hedges and shrubs & 0.20 \\
Wooded countryside, many trees & 0.25 \\
Small town with trees and shrubs & 0.30 \\
Large city with tall buildings & 0.40
\end{tabular}

and cables and raises the amount of land needed to install a specific capacity of turbines. As a result of these factors, turbine spacing varies by site Sorensen (2017). The cases consisted in variations in the stream-wise, $\mathrm{Sx}$ and span-wise, Sz, spacing. The cases where categorized by letters, A-D. Case A is the base case with a standard spacing with a $\mathrm{Sx}=6 \mathrm{D}$ and $\mathrm{Sz}=3 \mathrm{D}$. The spacing was reduced to half in both direction, $\mathrm{Sx}=$ $3 \mathrm{D}$ and $\mathrm{Sz}=1.5 \mathrm{D}$ for case $\mathrm{C}$ while in case B Sx was kept at $3 \mathrm{D}$ but $\mathrm{Sz}$ was doubled to $3 \mathrm{D}$. Compared to case $\mathrm{A}$, $\mathrm{Sx}=6 \mathrm{D}$ was kept for case $\mathrm{D}$ while the $\mathrm{Sz}$ was reduced to half. The goal of the described arrangements is to analyze how the wake of the wind turbines behave when reduction in the specified direction are made and better understand how the land-use can be optimized when arranging multiple wind turbines in an array.

Impact of tower height: Wind speed will increase with the height because the friction at Earth surface is large. The rate of the increase of wind speed that is often used to characterize the impact of the roughness of the Earth's surface on wind speed is given as:

$$
\left(\frac{\mathrm{v}}{\mathrm{v}_{0}}\right)=\left(\frac{\mathrm{H}}{\mathrm{H}_{0}}\right)^{\alpha}
$$

Where:

$\mathrm{v}=$ The wind speed at height $(\mathrm{H})$

$\mathrm{H}, \mathrm{v}_{0}=$ The nominal wind speed at height $(\mathrm{H})$

$\mathrm{H}_{0}$ and $\alpha=$ The friction coefficient

This can be translated into a substantial increase in power at greater heights. Table 1 and 2 gives the typical values of friction coefficient for various terrain
Table 3: Data sheet of wind turbine V136

\begin{tabular}{|c|c|c|c|}
\hline \multicolumn{2}{|c|}{ Turbine Model name } & \multicolumn{2}{|l|}{ V136 } \\
\hline \multicolumn{2}{|c|}{ Rated power (MW) } & \multicolumn{2}{|l|}{$3.45 \mathrm{MW}$} \\
\hline \multicolumn{2}{|l|}{ Wind class } & \multicolumn{2}{|l|}{ IEC IIA } \\
\hline \multicolumn{2}{|c|}{ Cut-In wind speed } & \multicolumn{2}{|l|}{$3.0 \mathrm{~m} / \mathrm{sec}$} \\
\hline \multicolumn{2}{|c|}{ Nominal wind speed $(8 \mathrm{~m} / \mathrm{s})$} & \multicolumn{2}{|l|}{$10.5 \mathrm{~m} / \mathrm{sec}$} \\
\hline \multicolumn{2}{|c|}{ Cut-out wind speed } & \multicolumn{2}{|l|}{$22.5 \mathrm{~m} / \mathrm{sec}$} \\
\hline \multicolumn{2}{|c|}{ Nominal rotor diameter $(\mathrm{m})$} & \multicolumn{2}{|l|}{136} \\
\hline \multicolumn{2}{|c|}{ Hub height (m) } & \multicolumn{2}{|l|}{$82-132$} \\
\hline \multicolumn{2}{|l|}{ Swept area $\left(\mathrm{m}^{2}\right)$} & \multicolumn{2}{|l|}{$12,469.0$} \\
\hline \multicolumn{2}{|l|}{ Frequency $(\mathrm{Hz})$} & \multicolumn{2}{|l|}{$60 / 50$} \\
\hline \multicolumn{2}{|l|}{ Generator type } & \multicolumn{2}{|c|}{ Asynchronous induction generator } \\
\hline \multicolumn{4}{|c|}{ Table 4: Data sheet of wind turbine V136 } \\
\hline Months & SHSA & DAL & FAR \\
\hline January & 6.369 & 6.027 & 5.785 \\
\hline February & 6.833 & 6.491 & 6.076 \\
\hline March & 7.366 & 7.024 & 6.345 \\
\hline April & 5.420 & 5.079 & 5.432 \\
\hline May & 7.749 & 7.407 & 7.302 \\
\hline June & 7.150 & 6.808 & 7.196 \\
\hline July & 9.068 & 8.726 & 8.041 \\
\hline August & 7.740 & 7.399 & 7.521 \\
\hline September & 8.356 & 8.015 & 7.456 \\
\hline October & 6.118 & 5.776 & 6.501 \\
\hline November & 6.010 & 5.669 & 5.933 \\
\hline December & 6.687 & 6.345 & 5.932 \\
\hline Annual average & 7.072 & 6.731 & 6.560 \\
\hline
\end{tabular}

characteristics. Oftentimes, for rough approximations in somewhat open terrain a value of $1 / 7$ (the "one-seventh" rule-of-thumb) is used for $\alpha$ (Zobaa and Bansal, 2011).

The optimal placement of wind farms under grid constraints: The integration of wind farms and their power outputs into the electrical grid affects the operation of the transmission system. Therefore, grid operators demand that newly integrated wind power plants into the electrical grid do not violate the transmission system constraints and proximity to the grid. Additionally, grid operators could declare regional upper bounds on wind farms due to economic and geographical concerns. Thus, the suggested wind farms are combined with a $132 \mathrm{kV}$ Iraqi grid system (Table 3 and 4).

From above a wind turbine is selected from manufacturer catalogues to satisfy the calculated annual energy for a certain location. It was found that a $3.45 \mathrm{MW}$ capacity wind turbine model number V 136 from VESTAS Company is the best wind turbine that satisfies the requirements of the present work. Selection of this wind turbine (V 136 type) was made after an overall comparison between different types of wind turbines. Every wind farm location is assumed to have height is $100 \mathrm{~m}$ of the selected model. Table 3 shows the data sheet of wind turbine V136. The power-speed curve for the selected wind turbine (V136) is shown 


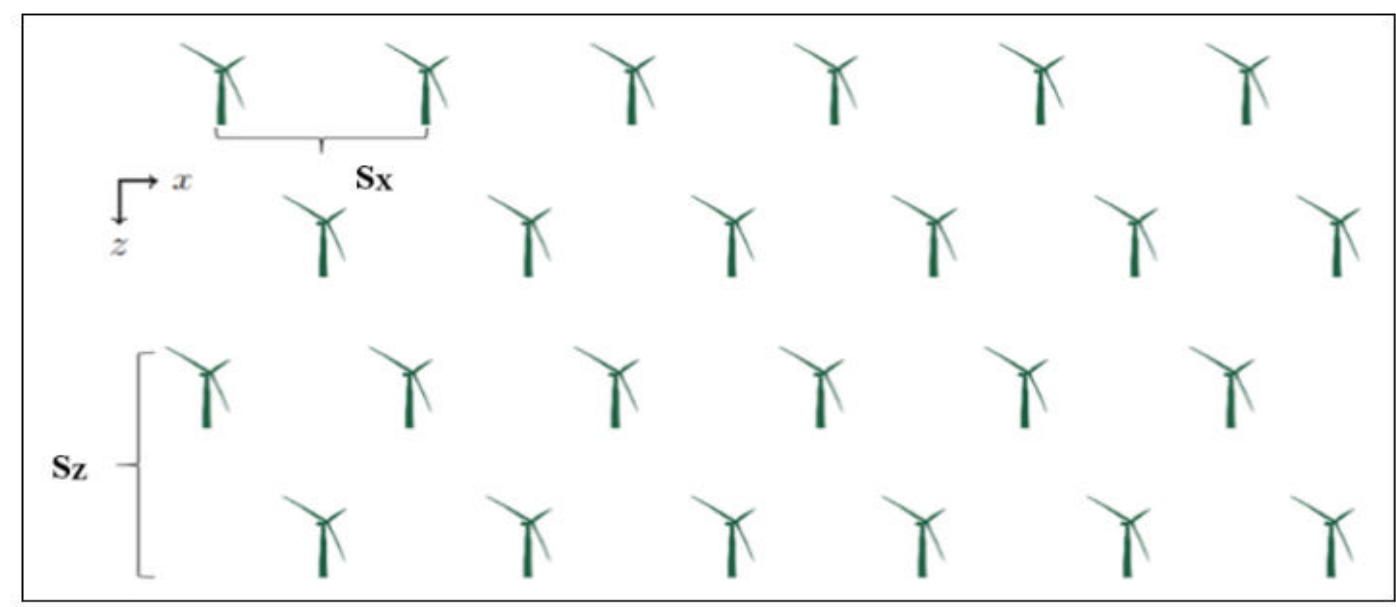

Fig. 6: Schematic detailing turbine spacing

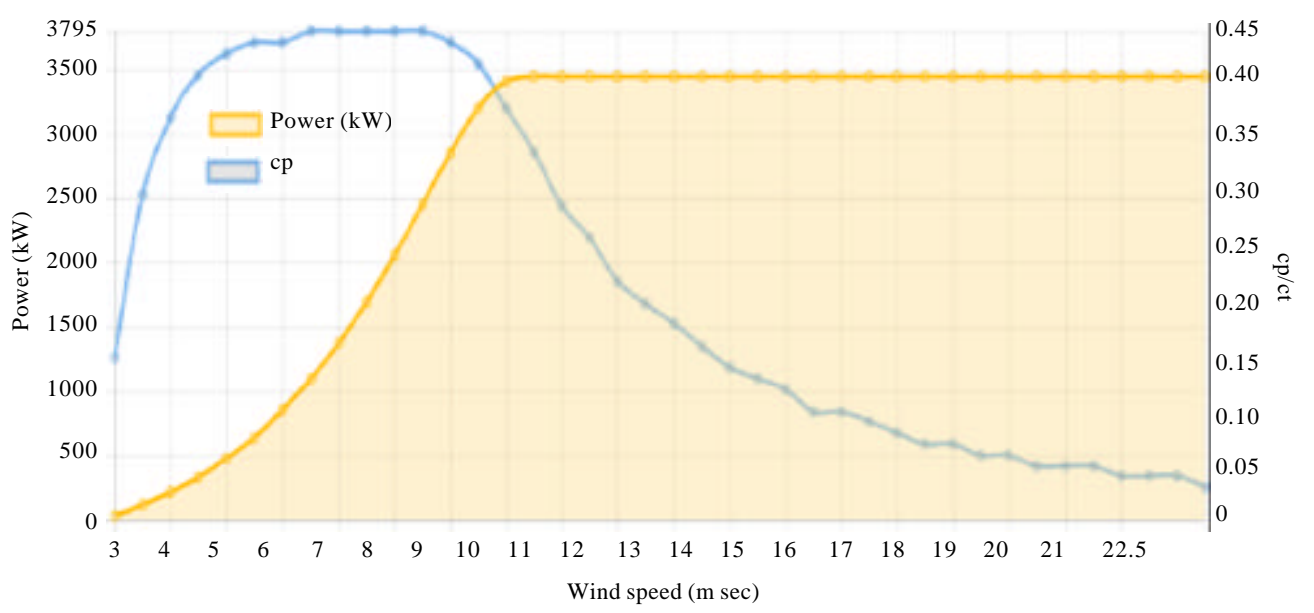

Fig. 7: Power-speed curve for Vestas V136 wind turbine

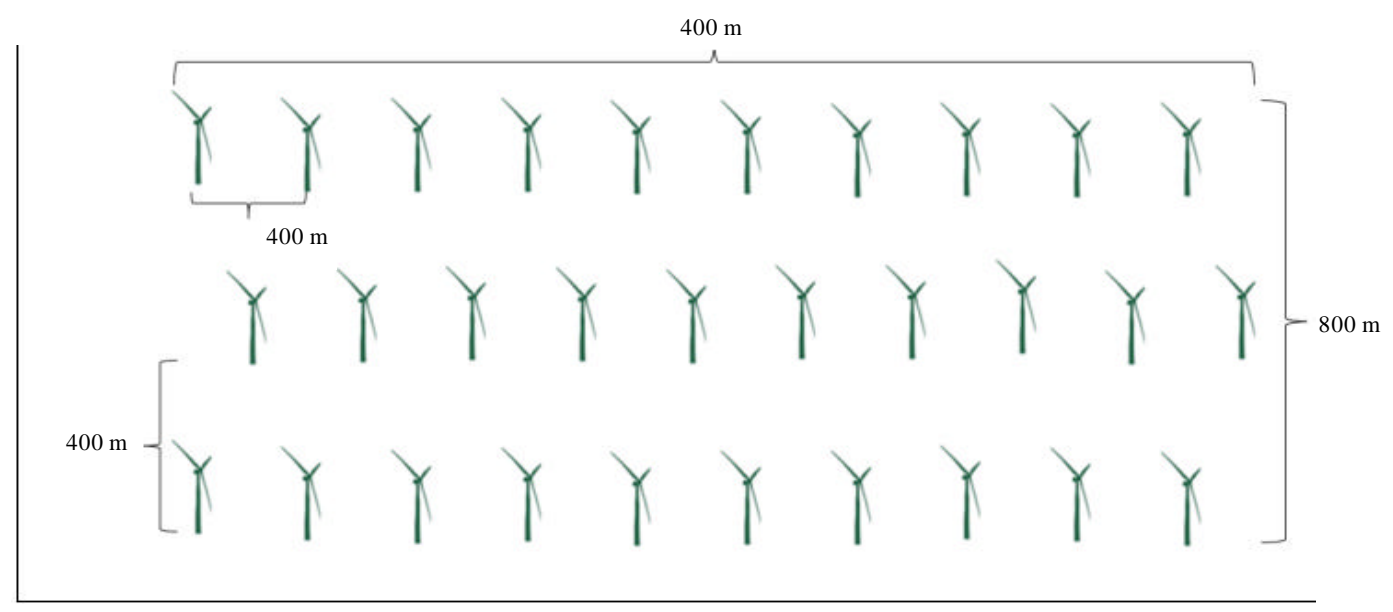

Fig. 8: Suggested distribution of the wind farm for Shaikh Saad 


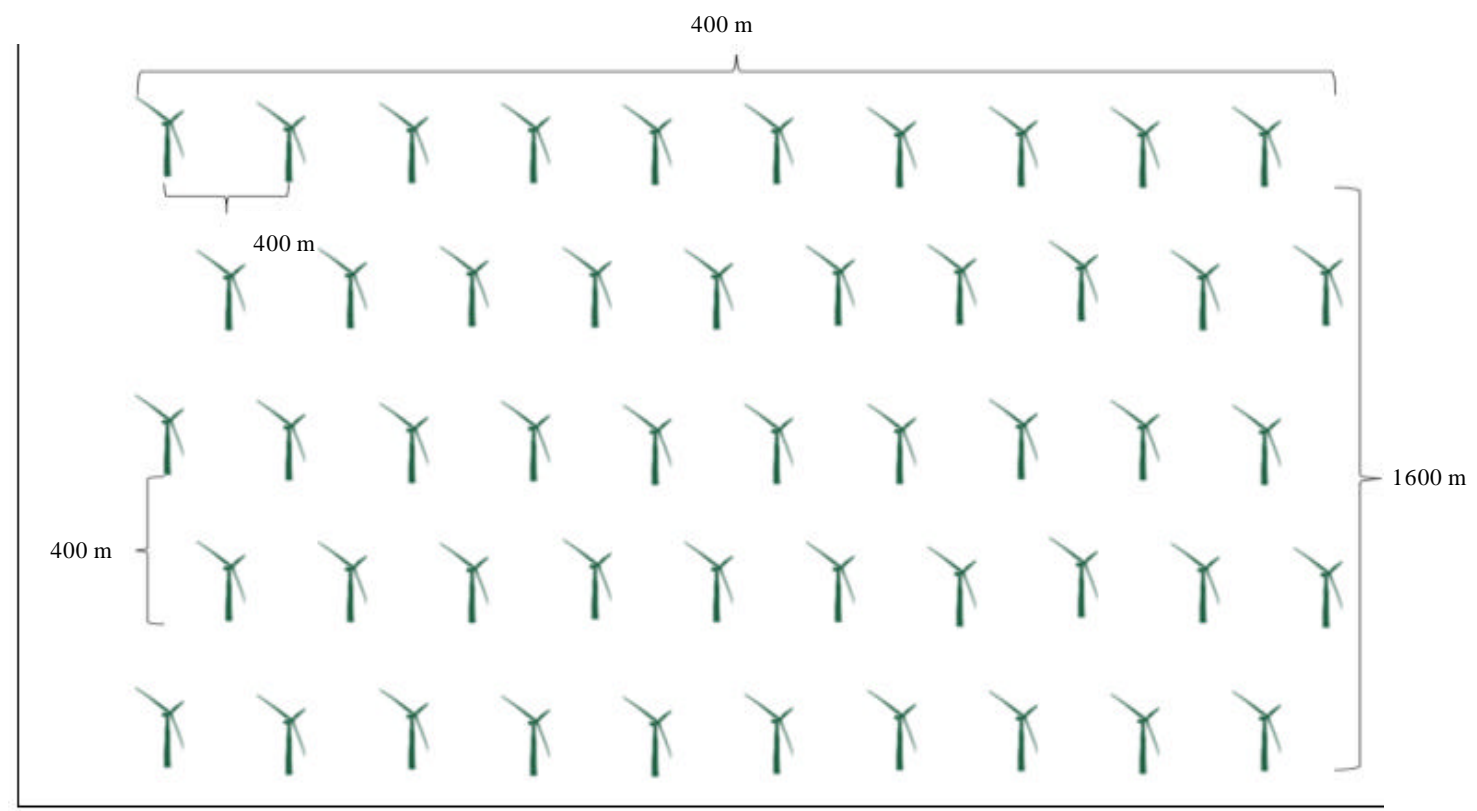

Fig. 9: Suggested distribution of the wind farm for Al-Djal and Al-Fajar

in Fig. 6-8. It indicates the amount of power produced by the wind turbine Model V136 for each wind speed value.

In this study it has been suggested, three wind farms include the following: Shaikh Saad and Al-Djal wind farms are located in the city of Wasit-Iraq, Al-Fajar wind farm is located in the city of Thi-Qar -Iraq. In Shaikh Saad is assumed to have 30 wind turbines (Nameplate capacity $=103 \mathrm{MW}$ ), Al-Djal and AL-Fajar are assumed to have 50 wind turbines of the selected model (Nameplate capacity $=172.5 \mathrm{MW})$. Shaikh Saad WF assumed connect to Shaikh Saad busbar $(132 \mathrm{kV})$ though transmission line for length $15 \mathrm{~km}$, Al-Djal WF assumed connect to Al-Djal busbar $(132 \mathrm{kV})$ though transmission line for length $9 \mathrm{~km}$ and Al-Fajar WF assumed connect to Al-Rifai busbar (132 kV) though transmission line for length $13 \mathrm{~km}$.The average annual wind speeds at height is $100 \mathrm{~m}$ for the above WF locations were measured in 2016 as indicated. The suggested distribution of the wind turbines for each of the four wind farms is shown in Fig. 9. It can be seen from these figures that the minimum space between each two wind turbines is taken as $400 \mathrm{~m}$ (case B). Therefore, the minimum overall area of Shaikh Saad, Al-Djal and Al-Fajar wind farm is about $3.2,3.2 \mathrm{~km}^{2}$, respectively.

\section{RESULTS AND DISSCUSION}

This study chapter presents the proposed the impact integration wind energy on different performance parameters of power systems. The proposed impact integration has been simulated using Power System Simulator for Engineer (PSS/E) Software Version 30.3 applied on the $132 \mathrm{kV}$ Iraqi grid system. The snapshot single line diagram of the $132 \mathrm{kV}$ Iraqi grid system is shown in Fig. 8. The results including the total generation of slack bus, voltage profile, the power flow of transmission lines loaded, the active and reactive power losses. In this research, study the impact of single and multiple wind farm site. Several scenarios with penetration levels from $25-100 \%$ and dispersion of wind generation have been investigated (Fig. 10).

It is known that increasing the generation in any electrical system is less generation of slack bus. Total generation of slack bus in Fig. 11 for different scenarios. Snapshot of voltage profile when integrating single and multiple wind farm for several scenarios in Fig. 12 and 13, respectively. Active and reactive power losses profiles of the system have shown in Fig. 14 and 15, respectively, It can be see that lowest active and reactive power losses when connect Al-Fajar (single WF) and (Shaikh Saad and Al-Fajar WFs). The loading as percentage of 4KUT-KUTO and KUTS-DJLA transmission line capacity for different scenarios in Fig. 16 and 17. It can be Fig. 18 the over load in MVA of 4KUT-KUTO and KUTS-DJLA without WF while in Fig. 19 with all WF within normal limits. 

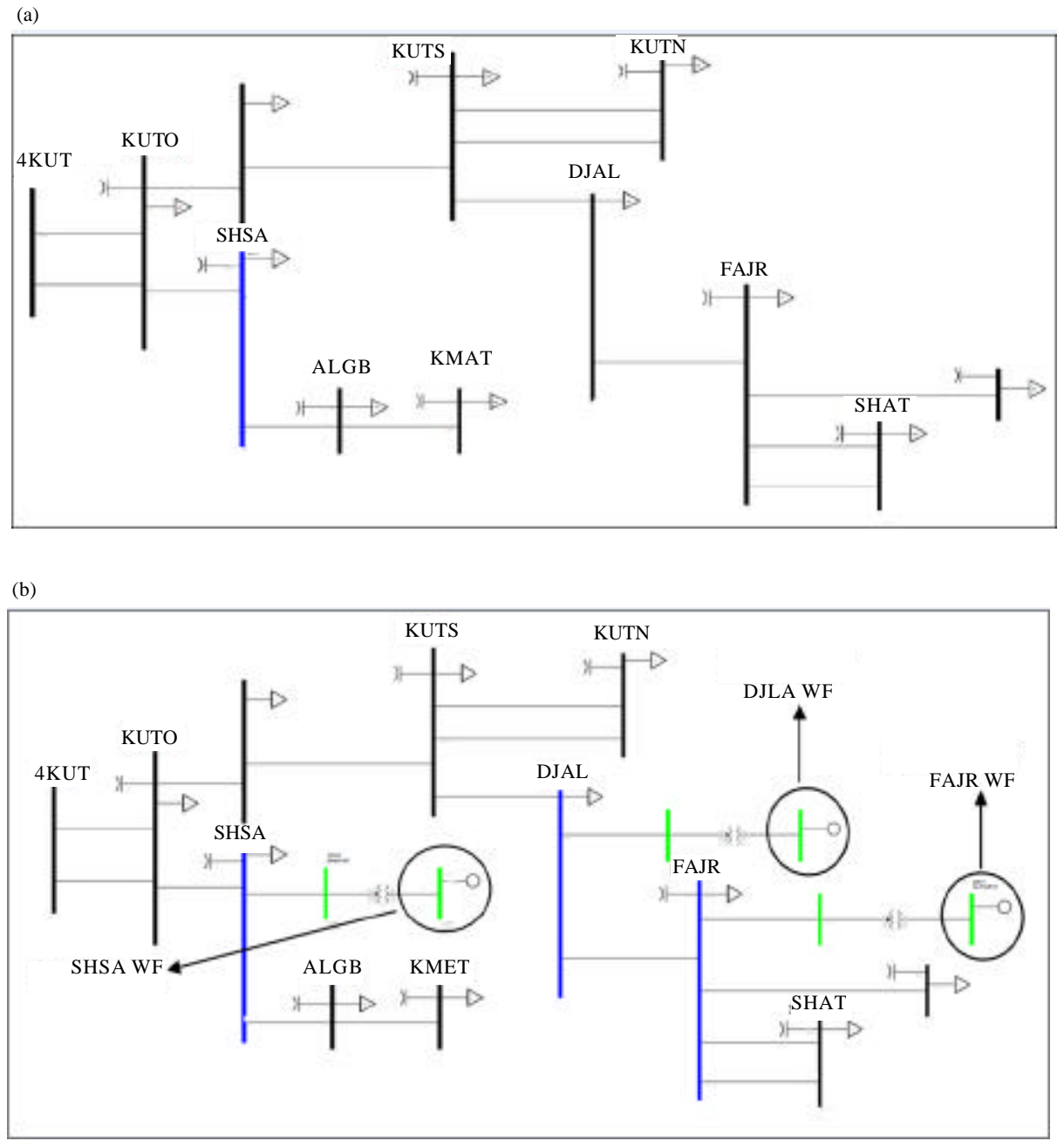

Fig. 10: The snapshot single line diagram of the $132 \mathrm{kV}$ Iraqi grid system; a) Without WF and b) With WF

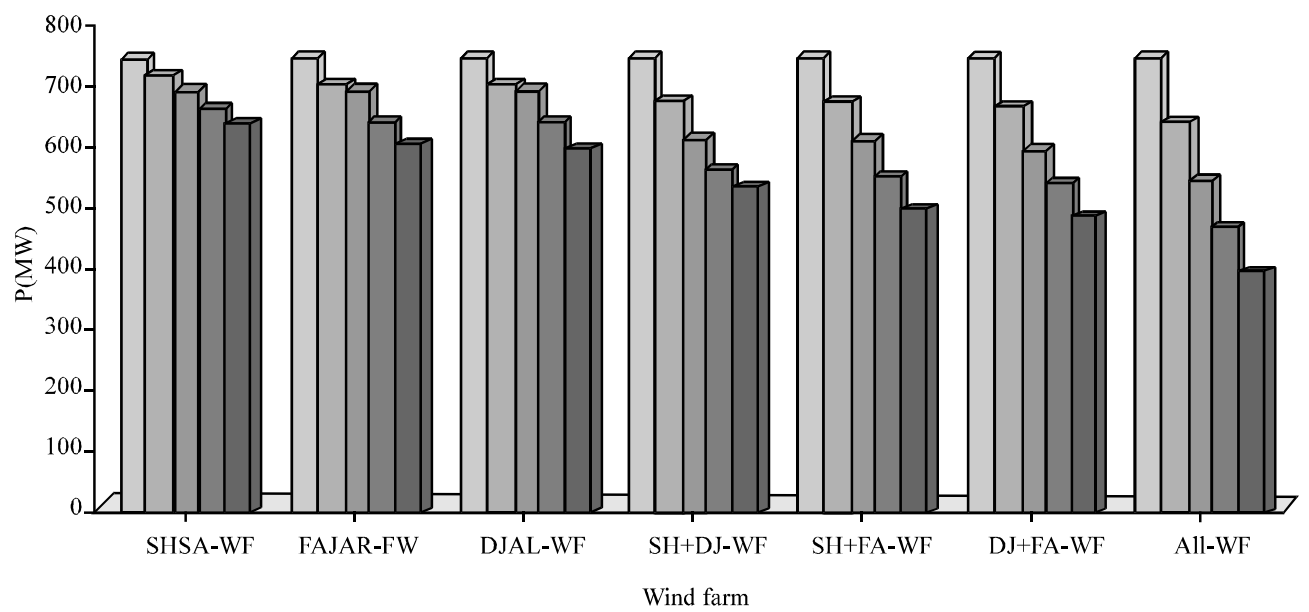

Fig. 11: The active power generation for slack bus 


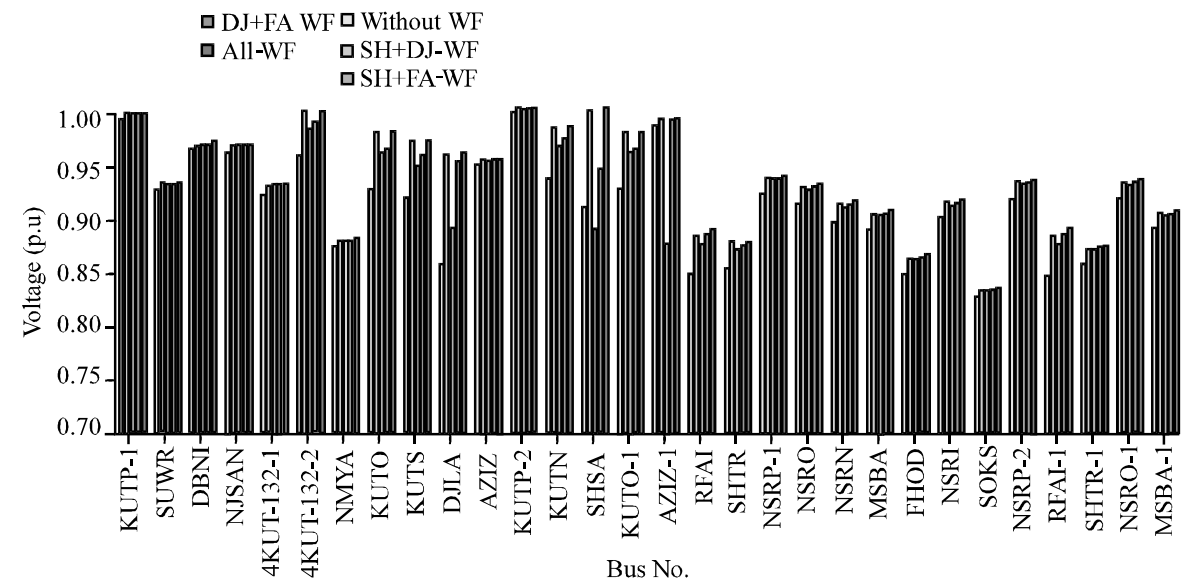

Fig. 12: Voltage profile when integrating single wind farm

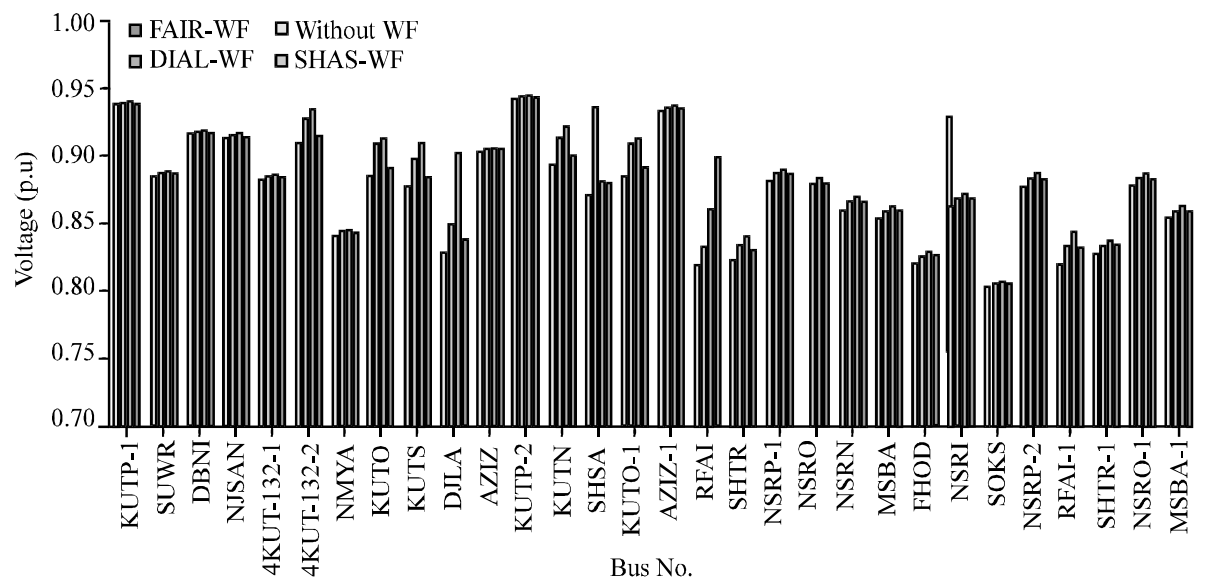

Fig. 13: Voltage profile when integrating multiple wind farm

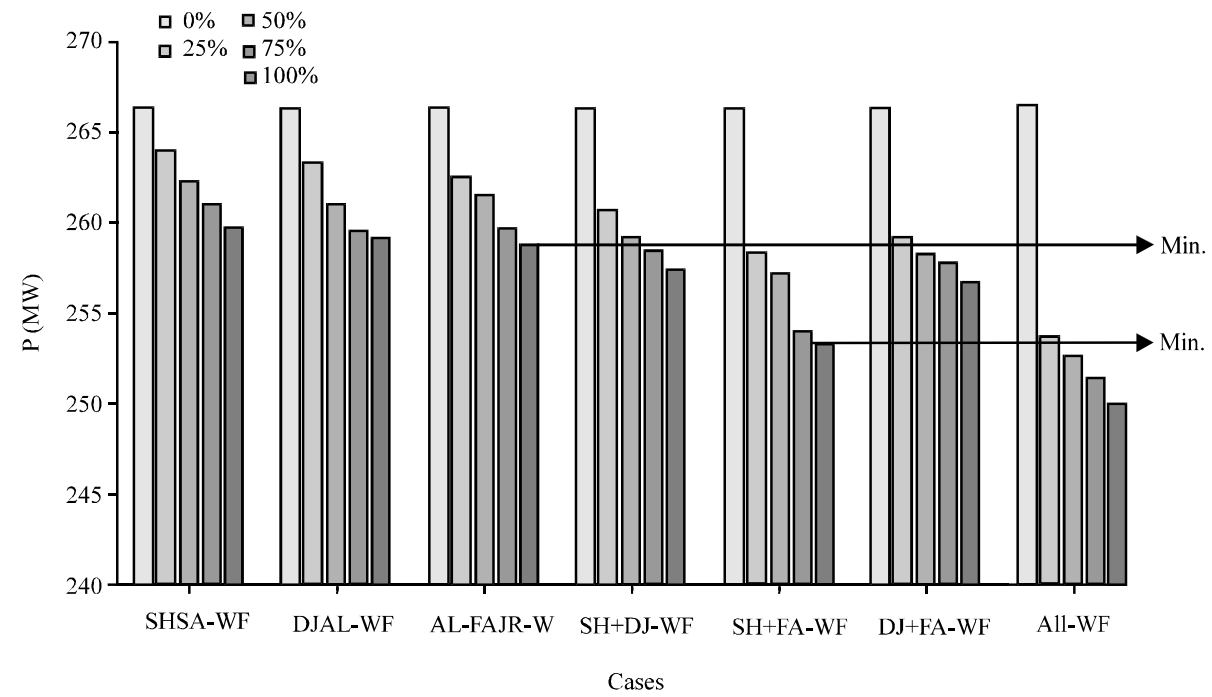

Fig. 14: Total active losses of system in different case 


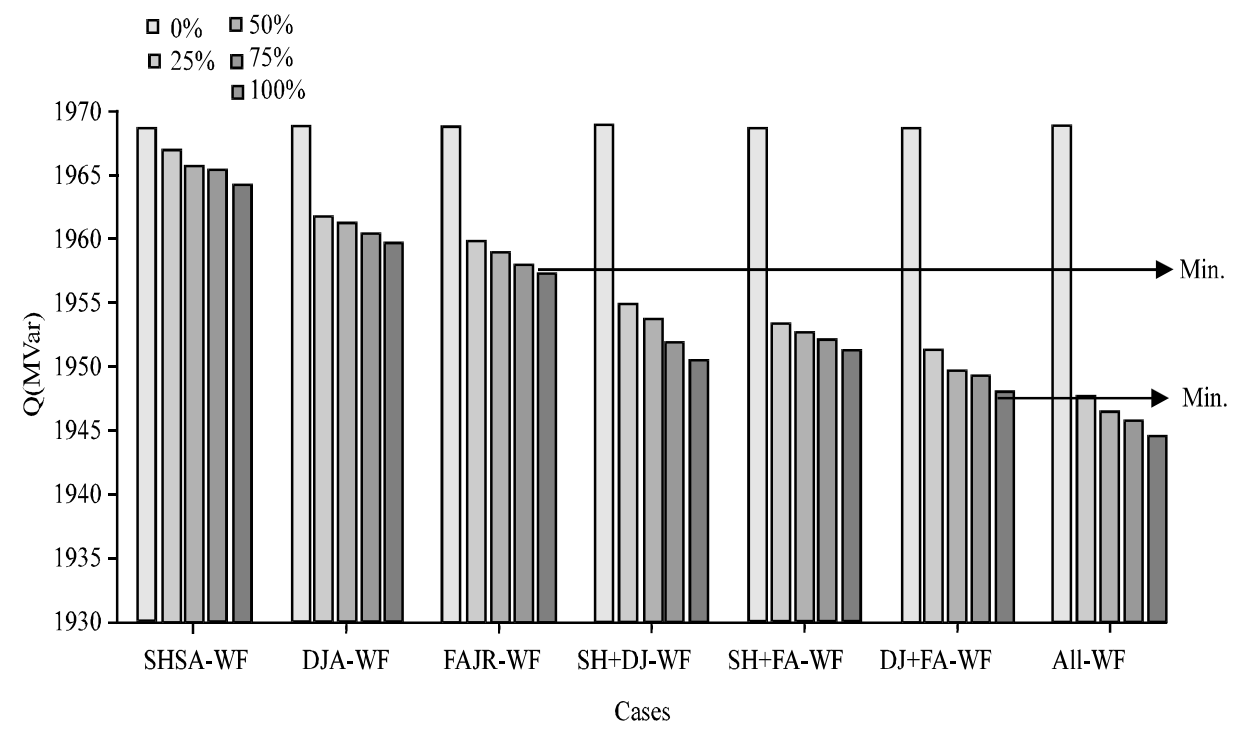

Fig. 15: Total reactive losses of system in different cases

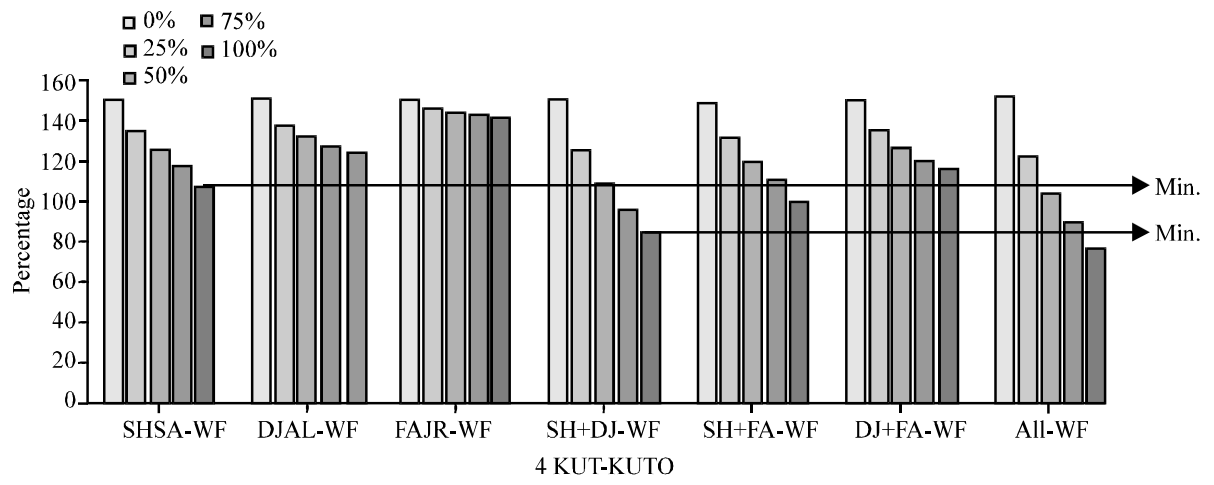

Fig. 16: The loading as percentage of 4KUT-KUTO transmission line capacity for different scenarios

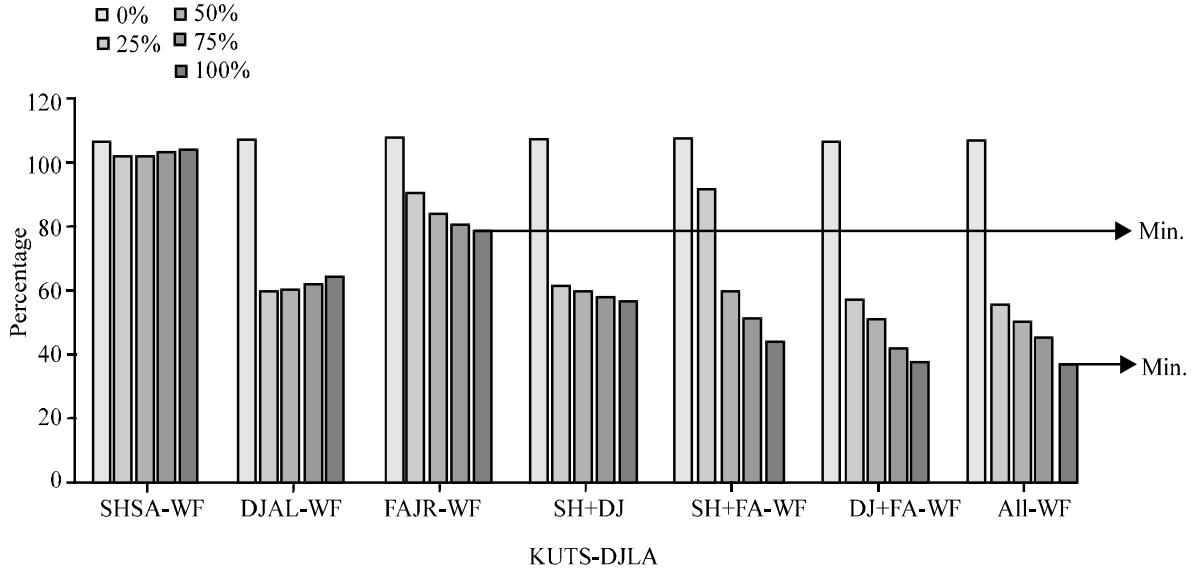

Fig. 17: The loading as percentage of KUTS-DJLA transmission line capacity for four different scenarios 


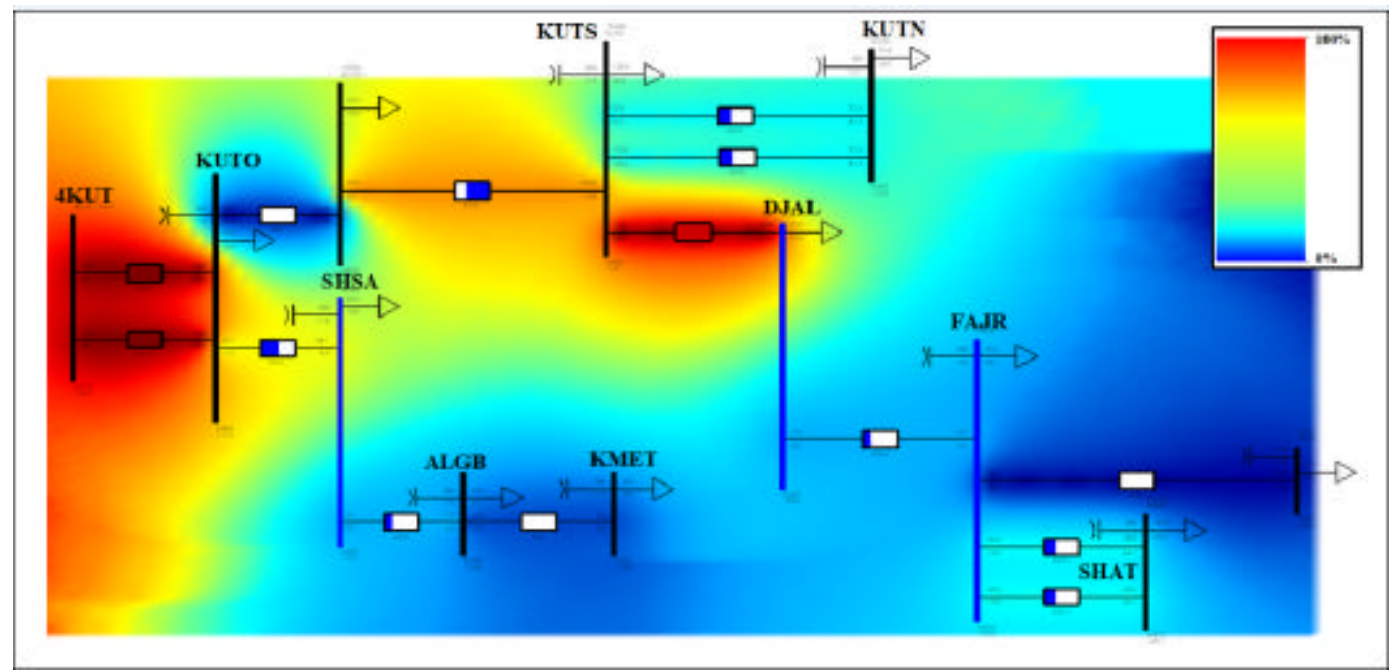

Fig. 18: The snapshot single line diagram of the $132 \mathrm{kV}$ Iraqi grid system of contouring $\backslash$ limit monitoring/Percentage of MVA limit (Max) without WF

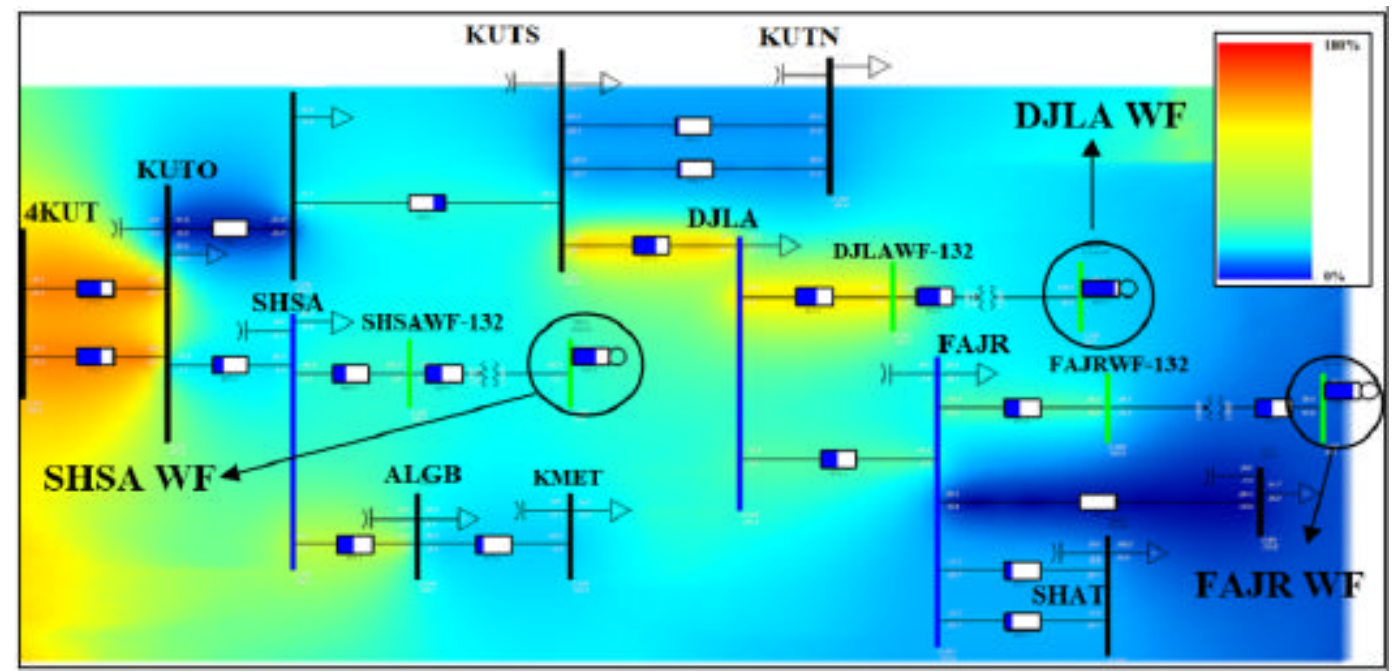

Fig. 19: The snapshot single line diagram of the $132 \mathrm{kV}$ Iraqi grid system of contouring Limit Monitoring $\backslash \%$ of MVA limit (Max) with all WF

\section{CONCLUSION}

Wind energy is the renewable energy that can be connected in an electrical network to meet the increased load demand. But, the wind production systems are extremely sensitive to the network disturbances. In this study the impact of integration of wind generator replacing synchronous generator in electric grid on the power flow are presented. The present research investigates the most suitable Iraqi site for wind farm power generation. The following conclusions are made.

\section{Impact of single wind farm site:}

- Al-Djal or Al-Fajar site has the highest values of total energy produced

- Al-Fajar site has the lowest values of total active and reactive power losses

- Overloaded lines in line 4KUT-KUTO and KUTS-DIA reduce when connected Shaikh Saad and AL-Fajar, respectively

\section{Impact of multiple wind farm site:}

- Al-Djal and Al-Fajar site (together) have the highest values of total energy produce 
- Shaikh Saad and Al-Fajar site (together) have the lowest values of total active and reactive power losses

- Overloaded lines in line 4KUT-KUTO and KUTSDJLA reduce when connected Shaikh Saad and Al-Fajar together

- Certainly when connect all three WF the impact integrating wind energy high among all other case investigated

\section{REFERENCES}

Cetinay, H., F.A. Kuipers and A.N. Guven, 2017. Optimal siting and sizing of wind farms. Renewable Energy, 101: $51-58$.

GWEC., 2017. Global wind report: Annual market update. Global Wind Energy Council, New York, USA. https://gwec.net/

Kalaivani, R. and V. Kamaraj, 2012. Application of hybrid PSOGA for optimal location of SVC to improve voltage stability of power system. Intl. J. Electr. Electron. Eng., 1: 31-36.

Mirhosseini, M., F. Sharifi and A. Sedaghat, 2011. Assessing the wind energy potential locations in province of Semnan in Iran. Renewable Sustainable Energy Rev., 15: 449-459.

Salman, G.A., 2015. Implementation SVC and TCSC to improvement the efficacy of Diyala electric network $(132 \mathrm{kV})$. Am. J. Eng. Res., 4: 163-170.
Sorensen, B., 2017. Renewable Energy: Physics, Engeneering, Environmental Impacts, Economics and Planning. 5th Edn., Elsevier, New York, USA., ISBN:9780128026106, Pages: 1056.

Villafafila, R., A. Sumper, A. Suwannarat, B. Bak-Jensen and R. Ramirez et al., 2007. On wind power integration into electrical power system: Spain vs. Denmark. Proceedings of the International Conference on Renewable Energies and Power Quality (ICREPQ) Vol. 5, IET, Stevenage, England, UK., pp: 1015 .

Wood, A.J., B.F. Wollenberg and G.B. Sheble, 2013. Power Generation, Operation and Control. 3rd Edn., Jhon Wiley \& Sons, Hoboken, New Jersey, USA., ISBN:9781118733912, Pages: 656.

Yaramasu, V., B. Wu, P.C. Sen, S. Kouro and M. Narimani, 2015. High-power wind energy conversion systems: State-of-the-art and emerging technologies. Proc. IEEE., 103: 740-788.

Zehar, K. and S. Sayah, 2008. Optimal power flow with environmental constraint using a fast successive linear programming algorithm: Application to the algerian power system. Energy Convers. Manage., 49: 3362-3366.

Zobaa, A.F. and R.C. Bansal, 2011. Handbook of Renewable Energy Technology. World Scientific, New Jersey, USA., ISBN-13:9789814289061, Pages: 851. 